Erratum

\title{
Erratum: Elshafie et al. Biological and Spectroscopic Investigations of New Tenoxicam and 1.10-Phenthroline Metal Complexes. Molecules 2020, 25, 1027
}

\author{
Hazem S. Elshafie ${ }^{1}$ (D) Sadeek A. Sadeek ${ }^{2}$, Ippolito Camele ${ }^{1, * \mathbb{D}}$, Hanem M. Awad ${ }^{3}$ and Amira A. Mohamed ${ }^{4}(\mathbb{D}$ \\ 1 School of Agricultural, Forestry, Food and Environmental Sciences, University of Basilicata, \\ Viale dell'Ateneo Lucano 10, 85100 Potenza, Italy; hazem.elshafie@unibas.it \\ 2 Department of Chemistry, Faculty of Science, Zagazig University, Zagazig 44519, Egypt; s_sadeek@zu.edu.eg \\ 3 Department Tanning Materials and Leather Technology, Centre of Excellence, National Research Centre, \\ El-Buhouth St., Dokki, Cairo 12622, Egypt; hanem_awad@yahoo.com \\ 4 Department of Basic Science, Zagazig Higher Institute of Engineering and Technology, Zagazig 44519, Egypt; \\ amiraabdeldayem6@gmail.com \\ * Correspondence: ippolito.camele@unibas.it; Tel.: +39-0971-205544; Fax: +39-0971-205503
}

check for updates

Citation: Elshafie, H.S.; Sadeek, S.A.; Camele, I.; Awad, H.M.; Mohamed, A.A. Erratum: Elshafie et al. Biological and Spectroscopic Investigations of New Tenoxicam and 1.10-Phenthroline Metal Complexes. Molecules 2020, 25, 1027. Molecules 2021, 26, 3662. https://doi.org/ $10.3390 /$ molecules 26123662

Received: 27 March 2020

Accepted: 16 December 2020 Published: 16 June 2021

Publisher's Note: MDPI stays neutral with regard to jurisdictional claims in published maps and institutional affiliations.

Copyright: (c) 2021 by the authors. Licensee MDPI, Basel, Switzerland. This article is an open access article distributed under the terms and conditions of the Creative Commons Attribution (CC BY) license (https:// creativecommons.org/licenses/by/ $4.0 /)$.
The authors of this paper [1] have agreed they would like to add Hanem M. Awad as the fourth co-author, as she made a significant contribution to the cytotoxicity tests.

The authors apologize for not including her in the original paper and for any inconvenience caused to the readers by this change.

The correct authorship should be as follows:

Hazem S. Elshafie ${ }^{1}$, Sadeek A. Sadeek ${ }^{2}$, Ippolito Camele ${ }^{1, *}$, Hanem M. Awad ${ }^{3}$ and Amira A. Mohamed ${ }^{4}$

1 School of Agricultural, Forestry, Food and Environmental Sciences, University of Basilicata, Viale dell'Ateneo Lucano 10, 85100 Potenza, Italy

2 Department of Chemistry, Faculty of Science, Zagazig University, Zagazig 44519, Egypt

3 Department Tanning Materials and Leather Technology, Centre of Excellence, National Research Centre, El-Buhouth St., Dokki, Cairo 12622, Egypt

4 Department of Basic Science, Zagazig Higher Institute of Engineering and Technology, Zagazig 44519, Egypt

\section{Reference}

1. Elshafie, H.S.; Sadeek, S.A.; Camele, I.; Awad, H.M.; Mohamed, A.A. Biological and Spectroscopic Investigations of New Tenoxicam and 1.10-Phenthroline Metal Complexes. Molecules 2020, 25, 1027. [CrossRef] [PubMed] 